\title{
Os sentidos do aprender a ser indígena e o viver a infância da criança Terena
}

\author{
Marta Regina Brostolin ${ }^{1}$ \\ brosto@ucdb.br
}

\author{
Evelyn Aline da Costa de Oliveira ${ }^{2}$ \\ evelynaline7@yahoo.com.br
}

\section{Resumo}

O presente trabalho teve por objetivo investigar a criança Terena, os sentidos do aprender indígena por meio do brincar e da relação com os adultos, cultura e comunidade. O foco da pesquisa se centrou na Aldeia Buriti, localizada em Dois Irmãos do Buriti, no Estado de Mato Grosso do Sul. Sendo um estudo etnográfico, a pesquisa oportunizou conhecer a história do povo Terena, a educação das crianças e suas aprendizagens a partir das experiências cotidianas que contribuem para a construção da identidade na infância. Foram entrevistados pais, avós, crianças e acadêmicos indígenas que moram na Aldeia Buriti e realizada uma oficina de desenho livre com o intuito de perceber a representação do brincar para a criança Terena. Os resultados evidenciam o orgulho que as crianças têm de ser índio e de participarem ativamente de todos os acontecimentos importantes para a Aldeia.

Palavras-Chave: criança Terena; infância; brincadeira; aprendizagem.

1 Doutora em Desenvolvimento Local pela Universidade Complutense de Madri (2005). Professora da Universidade Católica Dom Bosco.

2 Mestranda do Programa de Pós-Graduação, Mestrado e Doutorado em Educação da Universidade Católica Dom Bosco. 


\title{
The senses of learning to be indigenous and to live the childhood of the Terena child
}

\begin{abstract}
This study aimed to investigate the child Terena indigenous way of learning through play and the relationship with adults, culture and community. The focus of the research has focused on Buriti Village, located at Dois Irmãos do Buriti, in the State of Mato Grosso do Sul As an ethnographic study, the research provided an opportunity to know the history of the Terena people, the education of children and their learning from of everyday experiences that contribute to the construction of identity in childhood. We interviewed parents, grandparents, children and indigenous scholars who live in the Village Buriti and held a workshop free design in order to realize the representation of playing for children Terena. The results show that children are proud to be Indian and to participate actively in all the important events for the Village.
\end{abstract}

Keywords: child Terena; childhood, play; learning.

\section{Considerações iniciais}

A pesquisa sobre a infância vem, nos últimos anos, expressando um significativo aumento, seja na produção de teses e dissertações, seja na constituição de grupos de pesquisa nacionais e internacionais. A ampliação da produção se fez acompanhar nas investigações mais recentes de uma distinção terminológica, ou seja, os termos infância e criança, muitas vezes tomados de forma indistinta, vêm sendo mais bem diferenciados.

Para Kulmann e Fernandes (2004 apud GOUVEA, 2009, p. 97) a infância é "a representação que os adultos fazem do período inicial da vida, ou como o próprio período vivido pela criança, o sujeito real que vive esta fase da vida". Portanto, a história da infância seria a história da relação da sociedade, da cultura, dos adultos, com essa classe de idade e a história da criança seria a história da relação das crianças entre si 
e com os adultos, com a cultura e com a sociedade (GOUVEA, 2009).

Desde o século XVIII, tem-se elaborado um conjunto de saberes sobre a infância, sendo este um conceito disputado entre os diversos campos do conhecimento. A infância ora é uma estrutura universal, constante e característica de todas as sociedades, ora é um conceito geracional, uma variável sociológica que se articula à diversidade da vida das crianças considerando a classe social, o gênero e o pertencimento étnico, ou seja, a infância ora é singular, ora é plural (ABRAMOWICZ, 2011).

Atualmente, existe uma nova concepção sociológica que considera as crianças como participantes de uma rede de relações e, como sujeitos sociais, são capazes de produzir mudanças nos sistemas nos quais estão inseridas, ou seja, as forças políticas, sociais e econômicas influenciam suas vidas ao mesmo tempo em que as crianças influenciam o cenário político, social e cultural. Nesse sentido, a infância é formada por sujeitos ativos, com características diferentes dos adultos. As crianças pertencem a diferentes classes sociais, gênero, espaço geográfico, etnia e culturas, isto é, são crianças concretas e contextualizadas, são membros de uma sociedade; atuam nas famílias, nas comunidades, em outros espaços, fazem parte do mundo, incorporam-no e, ao mesmo tempo, influenciamno e criam significados a partir dele (NASCIMENTO, 2011).

Nessa perspectiva se insere este estudo cujo olhar se volta para a criança Terena, sua infância, os sentidos do aprender a ser indígena por meio do brincar e da relação com os adultos, a cultura e a comunidade.

\section{A pesquisa: contexto e método}

O foco da pesquisa se centrou na Aldeia Buriti, uma das nove aldeias que formam a Terra Indígena Buriti, localizada no município de Dois Irmãos do Buriti, no Estado de Mato Grosso do Sul; ele teve por objetivo investigar os sentidos do aprender a ser indígena da criança Terena por meio das atividades cotidianas, como as brincadeiras, a relação com o ambiente, os ensinamentos repassados pela família e a contribuição da comunidade para o desenvolvimento moral e social dessa criança. A relevância da investigação se deve à pouca produção técnico-científica 
voltada para a criança indígena e, especificamente, da etnia Terena.

Sendo um estudo etnográfico, a pesquisa bibliográfica possibilitou conhecer a história do povo Terena, seu modo de viver em comunidade, em família, a educação das crianças, a relação destas com os pares, os adultos, a cultura, o ambiente, as brincadeiras, enfim, suas aprendizagens a partir das vivências, das experiências, do sentir, do observar e do praticar.

A pesquisa empírica ocorreu por meio das visitas mensais à aldeia Buriti durante dois anos, tempo de vigência do projeto Memória, percepção e sentidos do aprender dos Terena da Aldeia Buriti: subsídios para uma proposta de etnoeducação, desenvolvido com recursos da Universidade Católica Dom Bosco (UCDB) e da Fundação de Desenvolvimento, Ciência e Tecnologia do Estado de Mato Grosso do Sul (FUNDECT/MS), por uma equipe multidisciplinar ${ }^{3}$ e interinstitucional de pesquisadores ${ }^{4}$. A observação e o convívio com as crianças e familiares nas suas atividades cotidianas possibilitaram a coleta de dados, ou seja, as entrevistas, bem como a aplicação de uma oficina de desenho livre com as crianças cujas produções serão apresentadas posteriormente. Também foram entrevistados três acadêmicos indígenas da UCDB que contribuíram com suas memórias de infância.

\section{Os Terena: conhecendo um pouco de sua história}

Os Terena são povos indígenas pertencentes à família linguística Aruak que, na segunda metade do século XVIII, vieram do Chaco Paraguaio para o Brasil, instalando-se, principalmente, no Estado de Mato Grosso do Sul. Lutaram com os soldados brasileiros em defesa de suas terras na Guerra do Paraguai e ajudaram na construção das linhas telegráficas para ligar o trecho Cuiabá até a fronteira da Bolívia e o Paraguai (CRUZ, 2009).

Até o final do século XVIII, o índio se mantinha por meio da agricultura, da caça, da pesca e da coleta e, com a mudança e perda do território, essas práticas incluíram o trabalho nas fazendas vizinhas. $\mathrm{O}$

3 Dois pesquisadores são formados em Pedagogia, dois em História, um em Biologia e outro em Geografia. 4 Três pesquisadores são da UCDB e os outros três são da Universidade Federal de Mato Grosso do Sul (UFMS). 
dia de trabalho começava com o raiar do sol e a primeira tarefa do dia era acender o fogo fora de casa para o preparo do mate.

De acordo com Silva (1949), em uma roda, todos da casa participavam da refeição repetidas vezes. Logo depois, os homens pegavam suas ferramentas e iam para o trabalho. Ao meio dia, quando o sol estava a pino, voltavam a casa para o almoço. Geralmente, alimentavam-se de arroz, feijão e carne seca e, separadamente, sentavam para comer a refeição. Depois do almoço, faziam a sesta até o sol se apresentar oblíquo; então, participavam de uma nova rodada de mate e seguiam para o trabalho. Enquanto isso, as mulheres e crianças arrumavam a casa e preparavam o jantar.

Segundo Silva (1949), moravam em casas retangulares, construídas com telhados de duas águas que desciam até próximo do chão, as paredes tinham 1,60 metros de altura e no centro três postes sustentavam uma viga central. A cobertura era feita de sapé ou folhas de acuri. Os utensílios usados para cozinhar, lavar e armazenar os alimentos variava entre cabaças, potes de barro e cestas.

A vestimenta do dia a dia era um saiote que ia da cintura até na altura dos joelhos, este era chamado de xiripá. Quando estavam na guerra, o xiripá era mais curto e de cor preta. O cabelo era amarrado e puxado para cima e para proteger os pés calçavam alpercatas de couro. Usavam pulseiras e enfeites nas pernas feitos de sementes, contas, dentes ou ossos de animais e metais como ouro e prata. Nas festas, usavam cocares de penas vermelhas e saiotes de plumas de ema, as penas de papagaios eram reservadas aos chefes, pois a ave era considerada um chefe também. A pintura corporal com tinta extraída do jenipapo e carvão vegetal era usada para o mesmo fim que os cocares e saiotes (SILVA, 1949).

Afastadas das áreas mais férteis que ocupavam anteriormente, as atuais reservas indígenas Terena se constituíram no início do século XX, por meio de três processos. As de Cachoeirinha, Bananal/Ipegue (TI Taunay e Ipegue) e Lalima, eram partes da área indígena anteriormente ocupada pelo grupo. Já em Capitão Vitorino (TI Nioaque), Moreira/ Passarinho (TI Pilad Rebuá) e TI Buriti (formada por nove aldeias) foram reagrupados remanescentes Terena vindos de outras regiões. No caso 
de Aldeinha e União, houve compra de terras pelos próprios índios. Atualmente, os Terena formam a segunda maior população indígena do Estado de Mato Grosso do Sul, mais de 20 mil de um contingente de 67.574 pessoas (BRASIL, 2010).

A Aldeia Buriti é a maior das nove aldeias localizadas na Terra Indígena Buriti. Possui 800 dos 2.090 hectares da área total e 848 moradores com 221 residências.

A organização social na Aldeia Buriti se estrutura em troncos familiares divididos em 11 vilas, cada vila tem um nome e o seu líder, que, com o cacique, formam o Conselho Tribal da aldeia. Os líderes dos troncos são, geralmente, pessoas mais velhas, que são responsáveis pela organização política dentro do próprio tronco e da aldeia. Se, por exemplo, o marido falece, a esposa assume o papel de líder do tronco, isso se ela tiver habilidade política. Um irmão ou um filho também pode assumir a liderança de um tronco em duas situações. A primeira é se a esposa não tiver a habilidade política necessária para assumir tal cargo e a segunda é se a esposa responsável pelo tronco falecer (PEREIRA, 2009).

Cada tronco estreita suas relações por uma questão de parentesco e laços consanguíneos; sendo assim, é extremamente importante a manutenção do tronco. Essa organização é mantida principalmente para delimitar e estabelecer ascendência e ancestralidade. Antigamente, as relações sociais eram estabelecidas por meio dos casamentos, mas, atualmente, a estrutura social dos Terena sofreu modificações devido aos fatores históricos e, principalmente, a intervenção do não índio na aldeia.

As atividades de pesca, caça e artesanato são inexistentes na aldeia Buriti devido à falta de matéria prima. Ainda existe a fabricação de colares e cocares com materiais alternativos, mas esses são para uso dos próprios indígenas nos dias de festas. A atividade econômica como a produção agrícola não é suficiente para a manutenção e subsistência das famílias e, por isso, os índios se empregam nos frigoríficos, fazendas e usinas da região. O governo disponibiliza cestas básicas, aposentadoria e bolsa-escola, para ajudar na complementação da renda.

$\mathrm{Na}$ aldeia, atualmente, existem práticas religiosas trazidas pelo não índio, como o catolicismo e o protestantismo, sendo a maioria da 
população católica. Algumas atividades xamânicas são realizadas, mas não são aceitas pelos evangélicos (protestantes). O batismo das crianças, por exemplo, é realizado na igreja católica e depois por uma pessoa que desempenha funções religiosas na aldeia. Os evangélicos não aceitam o batismo das crianças pelo pajé, até porque a crença não admite essas práticas (PEREIRA, 2009).

A religião do não índio promoveu mudanças também nas festas e comemorações realizadas na aldeia. A festa católica de São Sebastião é realizada em comemoração ao santo padroeiro da aldeia. A comunidade inteira se mobiliza na realização dessa festa, por ser uma promessa que passa de geração a geração, para agradecer ao santo que livrou e protegeu os habitantes de uma peste. As comemorações começam no dia $1^{\circ}$ de novembro, quando os fuzileiros ${ }^{5}$, levando a imagem de São Sebastião, começam a visitar as casas de fazendas nas redondezas de Buriti. No dia $1^{\circ}$ de janeiro, a procissão entra novamente na aldeia e as famílias visitadas recebem os fuzileiros sempre com muita festa e comida. Finalmente, no dia 19 de janeiro, retornam para a igreja e celebram a festa.

Outra comemoração importante na aldeia é o dia do índio. Segundo Cruz (2009, p. 67), "há um cerimonial pátrio, com o hasteamento da bandeira, hino, composição da mesa e discurso das lideranças locais e políticos (prefeito, vereadores), seguidas de atividades esportivas, danças do bate-pau e siputrema, churrasco comunitário e baile".

\section{As relações culturais e socais na comunidade Terena de Buriti}

Para o Terena, no casamento, o respeito e a fidelidade são atitudes importantes e levadas a sério. Os jovens moradores da aldeia Buriti pensam no casamento como um evento que marca profundamente a trajetória de vida e, por isso, casam-se com mais idade, o que não é muito comum em outras etnias indígenas. Alguns casamentos são marcados com muita antecedência para que todos os preparativos necessários para

5 Segundo Cruz (2009, p. 65), fuzileiros "é um grupo de índios Terena, moradores da aldeia, que cantam o hino de São Sebastião acompanhado de violão e caixa para fazer o cortejo da passagem do santo de uma casa para outra". 
o grande dia sejam realizados.

Depois do casamento, as cobranças de toda a comunidade e, principalmente, da família não param. O casal agora precisa manter a civilidade e a etiqueta não somente com as pessoas mais próximas, mas com toda a aldeia, sempre respeitando a ordem e as responsabilidades adquiridas com o casamento. A família pouco intervém na vida íntima do casal, mas, se isso for necessário, o diálogo é a maneira mais utilizada para conselhos e repreensões.

A cerimônia do casamento mudou com o tempo. Antes, acontecia em cinco etapas e é explicado por Cruz (2009, p. 58) da seguinte maneira:

1. combinações prévias do casamento, que cabia aos pais; 2 . o noivo era acompanhado à casa da noiva, onde passa a integrar a família da noiva; 3. o tapete de piri ou hituri simboliza o casal; 4 . a coleta de mopó, feita pelas famílias dos noivos antes do casamento, simboliza a aliança; 5 . o casamento é sancionado pelo pai da noiva.

Hoje, a primeira, segunda e quinta etapas são mantidas, a cerimônia civil é feita no posto da Fundação Nacional do Índio (Funai) e a cerimônia religiosa, na igreja católica ou evangélica localizada dentro da aldeia. A realização da cerimônia, independente de ser tradicional com todos os rituais e vestimentas adequadas para a ocasião ou, com uma cerimônia religiosa adquirida dos não índios, deve ter sempre o baile com muita música e comida.

Entre o povo Terena, a chegada de uma criança é esperada com muita expectativa. Quando a gravidez é descoberta, a família inteira passa pelo processo de resguardo. A mãe mantém uma alimentação saudável e equilibrada, enquanto os parentes e o pai da criança passam pelo mesmo processo. Segundo Silva (1949), o nascimento hipuhicotihiurá entre os antigos Terena era acontecimento de grande importância, cercado de rituais mágicos. Marido e mulher se submetiam a um jejum protetor. A mulher era assistida pela mãe (même) e pela mãe do marido (imonzé). No caso de não ser a criança desejada, a mulher dava à luz em lugar afastado da casa.

Para o autor, após o nascimento da criança, o cordão umbilical (uró) era cortado pelo marido. O marido sem filho era chamado imá, ao nascer o primeiro filho passava a ser chamado de huá. Após o nascimento da 
criança, o marido ia buscar palmito de bocaiuva, que se acreditava auxiliar a mãe na amamentação do filho. $\mathrm{O}$ marido ou a própria mulher lavava a criança. A mulher repousava durante seis dias após o parto.

Quando o umbigo (uró) caía, era guardado para auxiliar os partos difíceis; se uma mulher tivesse alguma dificuldade durante a gravidez ou ao dar à luz, amarrava à cintura um uró já ressecado. A criança era carregada às costas pela mãe, em um cesto preso à fronte ou ao peito por meio de uma faixa denominada apoone. A união da criança com as gerações passadas é feita por meio do nome, escolhido pelos avós, e referente a algum antepassado. As crianças eram amamentadas até idade superior a cinco anos (SILVA, 1949).

Atualmente, toda a família Terena aguarda o nascimento da criança com muita expectativa. E, para seguir as tradições, as simpatias são feitas para saber o sexo do bebê, como, por exemplo, a simpatia da galinha e da tesoura. Segundo a acadêmica indígena do curso de Pedagogia da UCDB, Angelina Alcântara Mamedes, moradora da Aldeia Buriti, essas simpatias são feitas da seguinte maneira:

A simpatia da galinha é feita pela avó da criança que mata a galinha e vê o lado para onde o pescoço vira, se for para o lado onde o sol nasce, a criança vai ser menino, se for para o outro lado será menina. A simpatia do garfo é feita pela avó também e ela tem que virar a ponta do garfo para cima e jogar no chão. Se a ponta cair para cima, a criança vai ser menino e se cair para baixo vai ser menina.

A forma como às crianças nascem mudou um pouco. Antigamente, as mães tinham seus filhos em casa com a ajuda da parteira. Hoje, o parto cesário é mais frequente que o parto normal, e o resguardo não é mais praticado de acordo com a cultura indígena, pois os avanços da medicina nas aldeias possibilitaram melhores condições de atendimento a saúde das crianças.

Do nascimento até a criança obter maior independência, a presença e o acompanhamento da mãe é importantíssimo para o desenvolvimento da linguagem, da coordenação motora e do comportamento moral e social. Apesar de toda a comunidade estar preocupada com o desenvolvimento dessa criança, é a mãe que passa a maior parte de seu tempo ao lado do filho, para que ele desenvolva por meio da experiência e do "aprender 
fazendo" tudo, ou pelo menos, boa parte daquilo que ele necessitará para sua vida. O pai possui papel secundário nesse primeiro momento da vida da criança; no entanto, ele será o maior responsável pela educação dos meninos quando estes forem mais velhos. É o pai que ensina a pesca, a caça e educa os meninos para a responsabilidade de cuidar das mulheres da casa (LIMA, 2008).

Os demais membros da comunidade assumem as crianças com papéis secundários de tios, avós, primos mais velhos que se responsabilizam nos cuidados de educar pelo exemplo em todos os espaços da aldeia. É comum se observar dentro das aldeias Terena "as mães de leite", que assumem, em determinados momentos, o filho de irmãs, primas, quando estas são impedidas de exercerem o papel de mãe por vários motivos, tais como um problema biológico ou fatores externos alheios à sua vontade (LIMA, 2008, p. 82).

Segundo Berger e Luckmann (1987) apud Lima (2008), é por meio da socialização primária que a comunidade indígena cria na consciência da criança a abstração progressiva dos papéis e atitudes particulares dos outros para papéis e atitudes em geral. Por meio das pessoas que têm significado para elas (pai, mãe, avós, tios, primos), é que as crianças aprendem valores e atitudes que são importantes para a sua formação. Essas características as levam a se reconhecerem e, ao mesmo tempo, serem reconhecidas como membros dessa ou daquela comunidade.

\section{Os sentidos do aprender a ser indígena e o viver a infância da criança Terena}

Cada povo possui e preserva sua história e mantém uma identidade própria que o identifica. Essa identidade no povo Terena está estritamente ligada com as formas de organização, ensino/aprendizagem e comportamentos tidos como fundamentais para a manutenção do $e$ thos ${ }^{6}$ Terena. Por isso, é necessário prezar algumas atitudes no casamento, no convívio familiar, nos cargos políticos e nos relacionamentos com os

6 De acordo com Pereira (2009, p. 83), o ethos Terena seria articulado a partir de uma concepção muito particular da condição humana, identificada a certos parâmetros de conduta, agrupados sob o rótulo geral de civilidade. 
não índios e fazer dessas atitudes a diferença positiva para o exemplo e experiência das outras gerações.

Segundo Pereira (2009, p. 85):

Os Terena cultivam com dedicação e refinado interesse alguns atributos consideráveis imprescindíveis às figurações sociais de seus troncos e aldeias. Esses atributos dizem respeito a determinadas atitudes comportamentais e disposição para a sociabilidade. Numa perspectiva mais distanciada, seria razoável propor que tais atributos são aprendidos como co-extensivos à própria condição de humanidade, segundo a concepção que ela recebe na formação social Terena.

O convívio familiar também revela uma importante parte da identidade Terena, e este é estimulado principalmente nos afazeres domésticos, na participação com os preparativos das festas e no diálogo com os pais. O respeito aos mais velhos e o "saber ouvir para aprender" são atitudes fundamentais na educação das crianças, que desde pequenas aprendem que a experiência adquirida com as pessoas mais velhas servirá para a vida toda.

A família participa ativamente na educação social e moral da criança indígena. $\mathrm{O}$ fazer, o brincar e o viver são ações presentes no cotidiano da infância Terena. A liberdade para a criança indígena é importante, porque, por meio da experiência adquirida por essa liberdade, as noções sociais e morais serão construídas ao longo da vida. Mas sempre a liberdade é supervisionada pela mãe ou por outro adulto da família. Cruz (2009, p. 145) observou em sua pesquisa que "a criança da Aldeia Buriti transita por vários lugares da aldeia e explora seu ambiente desde muito pequena".

A autora ainda acrescenta que para a família a educação é primordial na vida das crianças, e todos os integrantes dela colaboram com esse processo, mantendo o diálogo sempre. As correções são feitas por meio de longas conversas, sem o uso da força. Para o Terena, o "ouvir para aprender" é constante na educação, e ouvir os mais experientes é fundamental na aprendizagem. Para isso, as crianças são ensinadas desde cedo a respeitarem e obedecerem aos mais velhos.

A maneira que a família Terena ensina possibilita às crianças 
aprenderem a cooperar em todos os lugares onde elas estão. Os pais esperam que cada ensinamento seja vivenciado e praticado dentro e fora da aldeia. O ensino com os cuidados da casa, auxílio na preparação das festas, tudo é feito e dividido de acordo com a idade e habilidades que as crianças possuem. A coletividade é marca dos Terena. Um sempre ajuda o outro, independente da situação financeira ou do reconhecimento dessa ajuda mais tarde, até porque o reconhecimento virá sem dúvida.

Na cultura Terena, a comunidade exerce papel fundamental na transmissão de saberes tradicionais, pois possui sabedoria para ser comunicada e transmitida por seus membros, que contribuem na formação da identidade de todos. Na aldeia, a aprendizagem acontece a todo momento, em qualquer lugar e em qualquer tipo de relação social (LIMA, 2008).

Cruz (2009, p. 146) mostra claramente como os Terena percebe a criança:

Geralmente, o indígena considera cada criança um espírito único, com seus talentos próprios a oferecer ao seu grupo. Para os Terena da Buriti, as crianças são seres muito especiais, oferecem carinho e atenção que favorece a possibilidade de se constituírem em autoconfiança.

A população Terena aprende e ensina seu mundo para as suas crianças. É nas relações sociais que são elaborados e expressos os novos conhecimentos e se fazem essa reflexão sobre o mundo ao seu redor, ao mesmo tempo em que são vivenciados os processos de ensinoaprendizagem como fonte inesgotável de experiências (LIMA, 2008).

Na aldeia, não há um grupo ou uma instituição responsável para a transmissão dos saberes tradicionais. Todo conhecimento deve ser compartilhado no momento apropriado, respeitando a idade de cada um. Assim, na comunidade, as meninas costumam saber sobre a menstruação no dia em que esta ocorre, não há relato sobre a menarca entre as meninas, pois a responsabilidade de informar sobre o que ocorre é da mãe ou da avó materna, na ausência destas, uma parenta mais próxima.

O aprender fazendo é a principal característica da educação Terena constituída de muita paciência; é por meio desse ato que o pai ensina o filho como deve proceder, de maneira detalhada, num vaivém de 
repetições, dando condições de a criança obter a melhor aprendizagem. O tempo dos adultos dispensado para a criança indígena é muito valoroso, não existe pressa para terminar as atividades, e os adultos sempre estão dispostos a repetir o que se está ensinando, por muitas e muitas vezes, até mesmo porque todas as atividades que devem ser aprendidas possuem uma aplicabilidade na vida diária: o cuidado com a criação, pegar a galinha para a refeição, colher milho, debulhar, separar a palha, descascar a mandioca, arrancar a mandioca. São atividades que se aprendem brincando diariamente.

O respeito pelos idosos da aldeia, atribuído aos longos anos de vida e ao saber adquirido, faz com que os mais jovens carreguem dentro de si valores da cultura indígena Terena. A confiança estabelecida contribui para que as ordens sejam simplesmente aceitas, recebidas e ouvidas como conselhos, processo este que acontece com todos da aldeia, independente da idade. Caso uma pessoa mais velha perceba uma atitude inadequada de uma pessoa mais jovem, imediatamente chama sua atenção, pois o indígena aprende que o aconselhamento passa necessariamente por outra pessoa da comunidade, com a qual ele compartilha a sua história e o seu tempo social.

\section{O brincar da criança Terena}

O brincar é fundamental para o desenvolvimento. É a principal atividade das crianças quando não estão dedicadas as suas necessidades de sobrevivência (repouso, alimentação etc.). Brincar é envolvente, interessante e informativo. Envolvente porque coloca a criança em um contexto de interação em que suas atividades físicas e fantasiosas, bem como os objetos que servem de projeção ou suporte delas, fazem parte de um mesmo contínuo topológico; interessante porque canaliza, orienta, organiza as energias da criança, dando-lhes forma de atividade ou ocupação; e informativo porque, nesse contexto, ela pode aprender sobre as características dos objetos, os conteúdos pensados ou imaginados (MACEDO; PETTY; PASSOS, 2005).

Na perspectiva da criança, brinca-se pelo prazer de brincar; no brincar, 
objetivos, meios e resultados se tornam indissociáveis e enredam a criança em uma atividade gostosa por si mesma, pelo que proporciona no momento de sua realização.

O brincar é sério, uma vez que supõe atenção e concentração. Atenção no sentido de que envolve muitos aspectos inter-relacionados, e concentração no sentido de que requer um foco, mesmo que fugidio, para motivar as brincadeiras. O brincar supõe também disponibilidade, já que as coisas mais importantes da vida da criança - o espaço, o tempo, seu corpo, seus conhecimentos, suas relações com pessoas, objetivos e atividades - são oferecidas a uma situação na qual ela, quase sempre, é a única protagonista, a responsável pelas ações e fantasias que compõem essa atividade (MACEDO; PETTY; PASSOS, 2005).

São diversas as formas de brincar da criança Terena, o acadêmico indígena do curso de Administração da UCDB, Osmanyr Bernardo Farias, também morador da Aldeia Buriti conta que:

As crianças costumam brincar no espaço fora de casa com areia, jogam queimada, bate-ombro. Costumam brincar de "bicho" que é quando as crianças pulam nas árvores de galho em galho e futebol. As meninas brincam juntas com os meninos, não há separação de brincadeiras por gênero. Apesar de hoje as crianças brincarem com carrinho e brinquedos industrializados, não deixaram de brincar com brincadeiras antigas. Antigamente faziam brinquedos com madeira de paineira e vaquinha de manga verde.

No período da infância, as brincadeiras assumem um papel importante, pois as atividades que sempre estão ligadas a um sentido real possibilitarão os ensinamentos dos conteúdos que ensinarão as crianças para a vida toda. A partir da observação realizada durante as visitas à aldeia, constatou-se que as brincadeiras preferidas das crianças Terena são o futebol, a flor, brincar de bicho (pular de galho em galho nas árvores da aldeia), queimada e com areia. Essas preferências foram evidenciadas na oficina de desenho livre, aplicada em uma das visitas com um grupo de crianças de 5 a 12 anos, cuja proposta era desenhar a brincadeira que mais gostava. Foram disponibilizados giz cera e papel e os desenhos abaixo ilustram a representação do brincar para a criança Terena. 


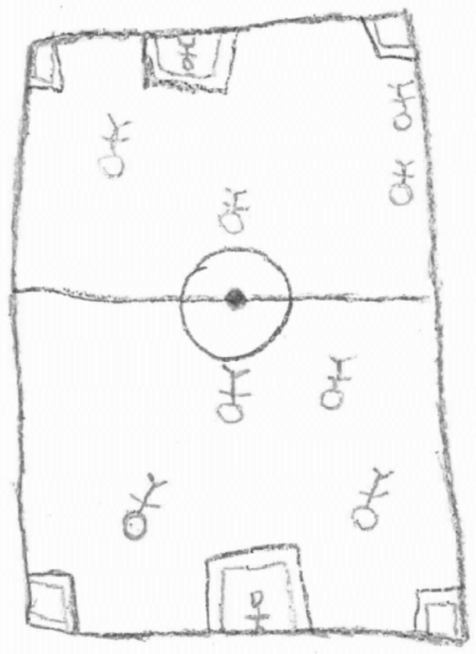

FIGURA 1 - Desenho da brincadeira do "brincar de bicho" de uma criança de 9 anos

Fonte: Dados da pesquisa.

Geralmente, todas as crianças brincam juntas. As meninas brincam com os meninos nas mesmas brincadeiras. Outra brincadeira praticada pelas crianças é a da flor.

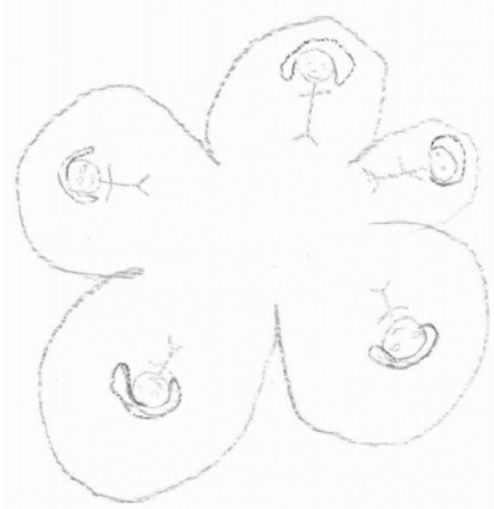

FIGURA 2 - Desenho da brincadeira da "flor" de uma criança 7 anos

Fonte: Dados da pesquisa. 
Para brincar, é necessário apenas um pedaço de galho de árvore para desenhar na areia e um grão de milho. A brincadeira começa quando uma flor é desenhada no chão, com a quantidade de pétalas correspondente ao número de participantes. Em cada pétala um número é colocado, como, por exemplo, os números 7, 10, 21, 42, 50, 70 e 100. O centro da flor (miolo) fica reservado para a brincadeira começar. Por sorteio, que é feito com o grão de milho, um número é escolhido. O jogador que estiver na pétala do número sorteado, deve ir para o centro da flor e gritar "stop", enquanto os demais participantes correm para lados opostos. Quando a palavra "stop" é ouvida, todos os outros que correram devem parar e virar "estátuas". Então, o participante que está no centro da flor, em três passos longos, deve encostar em alguém. Se conseguir, a pessoa tocada recebe um " $X$ " no número, se acumular três " $X$ ", estará fora da brincadeira. O vencedor será aquele que ficar por último.

Outra atividade que envolve crianças e adultos é o futebol, joga-se no dia a dia e também nas festividades, como em torneios intervilas, quando a comunidade se reúne para torcer por times masculinos e femininos.

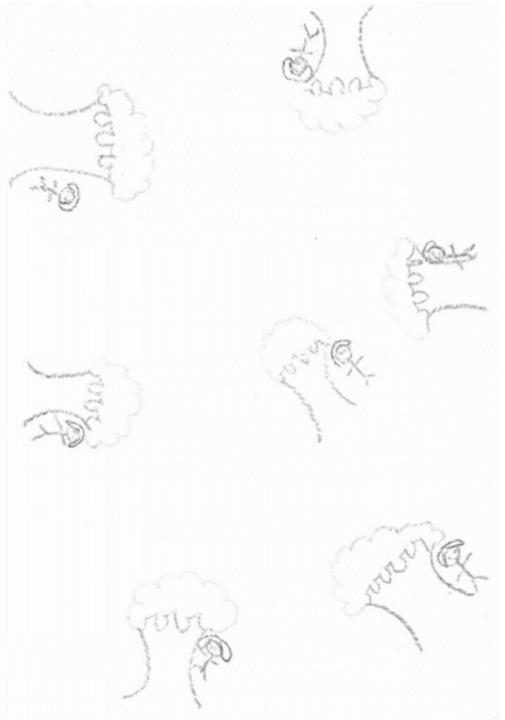

FIGURA 3 - Desenho de uma "partida de futebol" de uma criança de 10 anos

Fonte: Dados da pesquisa. 
Durante as visitas à aldeia, observou-se que as crianças brincam todas juntas e sempre das mesmas brincadeiras. É muito raro observar uma criança isolada do grupo fazendo outra atividade. Sempre ativas e alegres, brincam correndo pelas árvores explorando cada espaço da vila em que moram.

Em uma das longas conversas com a Dona Veriana (68 anos), tronco da Vila Tarumã, ela afirmou que as crianças brincam hoje de forma diferente que as do passado. Quando era criança, costumava brincar com as meninas de boneca feita de sabugo de milho. As brincadeiras eram divididas por gênero e jamais essa divisão era desrespeitada. Os meninos brincavam longe das meninas e as meninas mantinham essa distância, diferentemente do que acontece hoje, em que todas as crianças brincam juntas e com brincadeiras mais ativas. Ela ressalta ainda a influência da televisão nas brincadeiras das crianças e, principalmente, no comportamento coletivo que sofreu alterações.

Embora os brinquedos e as brincadeiras tenham mudado, as brincadeiras antigas não deixaram de ter sua importância na vida das crianças. Apesar da existência do computador, videogame e outros tipos de brinquedos, as crianças indígenas não passaram a ser individualistas ao ponto de permanecerem dentro de casa somente com o uso desses aparelhos. E, quando há brincadeiras desse tipo, as crianças convidam seus amigos para brincarem também e todos se divertem juntos.

\section{Considerações finais}

Cada criança, independente de raça, cor ou etnia, produz seu lugar na infância (SARMENTO; GOUVEA, 2009). Brincar, criar, pensar, pintar é próprio de toda criança, cada uma de acordo com sua cultura e poderes aquisitivos.

Para os Terena, os ensinamentos que transmitem as crianças perpassam principalmente pelo núcleo familiar. É de responsabilidade do grupo familiar a apresentação de valores étnicos, como o respeito mútuo, a solidariedade, o costume de "dar a benção". Essas aprendizagens, de responsabilidade da comunidade como um todo, são repassadas por 
meio da oralidade, comunicando e perpetuando a herança cultural de geração para geração. Uma das características desse processo educacional é a observação. Na aldeia, não são ditas muitas palavras para ensinar ou aprender, o olhar é a principal manifestação do amplo código social, por meio do qual acontece o processo educativo dos indivíduos $(\mathrm{COHN}$, 2005 apud LIMA, 2008).

Assim, a integração dos membros mais experientes com os menos experientes se dá de forma prazerosa, e as condutas, as regras sociais, as maneiras de cultivar a roça se dão por meio do diálogo e do exemplo, pois, ao longo do processo interativo, é que as crianças começam a desempenhar suas atividades sob orientação e guias de outros e, paulatinamente, aprendem a resolvê-las de forma independente.

Nas atividades diárias, as responsabilidades são divididas conforme a necessidade de cada uma das famílias, que mutuamente se ajudam, seja no cuidado com os filhos, seja na solidariedade da troca. O coletivo é a marca registrada da comunidade Terena, que não tem como mais importante o poder aquisitivo, mas sim a coletividade e a solidariedade com os outros membros.

Nesse ambiente, as brincadeiras assumem um papel significativo para as crianças indígenas, pois é por meio delas que aprendem conteúdos que serão usados para a vida toda, entendendo que essas atividades estão sempre ligadas a um sentido real, utilitário.

Dessa forma, a criança indígena constrói sua identidade no foco da socialização, a cultura é ensinada e aprendida por meio de conversas, da transmissão oral de todo o repertório cultural do grupo, por meio de gestos e atitudes que as crianças observam e compartilham. 


\section{Referências}

ABRAMOWICZ, A. A pesquisa com crianças em infâncias e a sociologia da infância. In: FARIA, A. L. G.; FINCO, D (Org.). Sociologia da Infância no Brasil. Campinas, SP: Autores Associados, 2011. p. 17-36.

BERGER, P. L.; LUCKMAM, T. A construção social da realidade: tratado da sociologia do conhecimento. Petrópolis, RJ: Vozes, 1987.

BRASIL. Caracterização demográfica etno-cultural dos Povos Indígenas do DSEI/FUNASA. [s.n.], 2010.

CRUZ, S. de F. A criança Terena: o diálogo entre a Educação indígena e a Educação escolar na aldeia Buriti. 2009. 191 f. Dissertação (Mestrado em Educação) - Universidade Católica Dom Bosco, Campo Grande, 2009.

COHN, C. Antropologia da criança. Rio de Janeiro: Jorge Zahar, 2005.

GOUVEA, M. C. S. de. A escrita da história da infância: periodização e fontes. In: SARMENTO, M.; GOUVEA, M. C. S. de. (Org.). Estudos da infância: educação e práticas sociais. 2. ed. Petrópolis: Editora Vozes, 2009. p. 97-118.

LIMA, E. G. de. A pedagogia Terena e a criança do PIN Nioaque: as relações entre família, comunidade e escola. 2008. 175 f. Dissertação (Mestrado em Educação) - Universidade Católica Dom Bosco, Campo Grande, 2008.

MACEDO, L. de; PETTY, A. L. S.; PASSOS, N. C. Os jogos e o lúdico na aprendizagem escolar. Porto Alegre: Artmed, 2005.

NASCIMENTO, M. L. B. P. Reconhecimento da Sociologia da Infância como área de conhecimento e campo de pesquisa: algumas 
considerações. In: FARIA, A. L. G.; FINCO, D (Org.). Sociologia da Infância no Brasil. Campinas, SP: Autores Associados, 2011. p. 37-54.

PEREIRA, L. M. Os Terena de Buriti: formas organizacionais, territorialização e representação da identidade étnica. Dourados, MS: Editora da UFGD, 2009.

SARMENTO, M.; GOUVEA, M. C. S. de. Estudos da Infância: educação e práticas sociais. 2. ed. Petrópolis: Editora Vozes, 2009.

SILVA, F. A. Mudança cultural dos Terena. São Paulo: Museu Paulista, 1949.

Recebido: $11 / 07 / 2013$

Aprovado: 11/11/2013 